\title{
Relación in vitro entre Cylindrocarpon cylindroides y Neonectria fuckeliana asociados a cancros fustales de Pinus radiata en Chile
}

\author{
(In vitro relationship between Cylindrocarpon cylindroides and Neonectria \\ fuckeliana associated with stem cankers on Pinus radiata in Chile)
}

\author{
Moisés Osorio ${ }^{1^{*}}$, Cristian González ${ }^{3}$, Rodrigo Morales², \\ Isabel Vives ${ }^{2}$, Eduardo Molina ${ }^{3}$, Juan Carlos Carmona ${ }^{3}$. \\ ${ }^{1}$ Ex-Académico, Universidad Austral de Chile, Asesor Privado. \\ 2Universidad Austral de Chile, Facultad de Ciencias Forestales y \\ Recursos Naturales, Laboratorio de Patología Forestal. \\ ${ }^{3}$ Asistente de Investigación Proyecto Fondo SAG-C6-110-NC-13 \\ *Autor para correspondencia: moisesyoguiloa@gmail.com
}

RECIBID0: 13 de Abril de 2014 APROBADO: 19 de Junio de 2014

LOS AUTORES DECLARAN NO TENER CONFLICTO DE INTERESES

Palabras clave: Cultivos, Cylindrocarpon cylindroides, Neonectria fuckeliana, cancros, Pinus radiata. Key words: Culture, Cylindrocarpon cylindroides, Neonectria fuckeliana, canker, Pinus radiata.

\section{RESUMEN}

Desde el punto de vista estrictamente micológico, se ha discutido por décadas la relación de Cylindrocarpon cylindroides como anamorfo de Neonectria fuckeliana, lo que entre otras consecuencias, ha incidido en la controversial ubicación taxonómica de este teleomorfo. Se añade a esto que en patología forestal se ha brindado poca atención a la presencia de $C$. cylindroides dentro del ciclo de la enfermedad causada por Neonectria fuckeliana en coníferas, razón por la cual los estudios específicos respecto de este anamorfo han sido también muy escasos. El presente trabajo tuvo como objetivo verificar la relación entre $C$. cylindroides y Neonectria fuckeliana, asociados a cancros en troncos de Pinus radiata en Chile, mediante el análisis de las características macro y micromorfológicas que ellos manifiestan en cultivos in vitro, además de análisis de tipo molecular. Se pudo constatar que ambos agentes dieron origen a colonias con idénticas características macro y micromorfológicas, destacando entre éstas la producción de abundantes conodióforos y microconidios del tipo Acremonium, el cual ya ha sido señalado en anteriores estudios como estado anamorfo de Neonectria fuckeliana. El que este mismo estado asexual del tipo Acremonium haya sido la manifestación in vitro tanto de $C$. cylindroides como de Neonectria fuckeliana, permitió confirmar la relación existente entre estos dos agentes en estudio, la que también fue ratificada mediante los análisis moleculares realizados.

\section{ABSTRACT}

From the point of view strictly mycological has been discussed for decades the relationship of Cylindrocarpon cylindroides as anamorph of Neonectria fuckeliana, which among other consequences, has influenced the controversial taxonomic status of this teleomorph. Add to this that in forest pathology has given little attention to the presence of $C$. cylindroides within the cycle of the disease caused by Neonectria fuckeliana on conifers, why specific studies regarding this anamorph have been very few. This study aimed to verify the relationship between $C$. cylindroides and Neonectria fuckeliana associated with cankers on trunks of Pinus radiata in Chile, by analyzing the macro and micromorphological characteristics they manifest in 
Relación in vitro entre Cylindrocarpon cylindroides y Neonectria fuckeliana - M.Osorio et al.

cultures in vitro, further analysis type molecular. It was found that both agents gave rise to colonies with identical macro and micromorphological characteristics, highlighting among them the production of abundant microconidia and conidiophores of Acremonium type, which has already been noted in previous studies as anamorph state of Neonectria fuckeliana. The asexual state that this same type of Acremonium has been the in vitro demons-tration of both C. cylindroides as Neonectria fuckeliana, allowed us to confirm the relationship between these two agents in the study, which was also ratified by the molecular analyzes performed.

\section{INTRODUCCIÓN}

Neonectria fuckeliana (C. Booth) Castlebury \& Rossman comb. nov. (syn. Nectria fuckeliana C. Boot) es un hongo comúnmente asociado a corteza de coníferas, entre las que se señalan Abies, Larix, Pinus, y Picea (Brayford et al. 2004). Gadgil et al. (2003) reportaron la presencia de este hongo, asociado a cancros en troncos de Pinus radiata en Nueva Zelanda, lo que constituyó el primer antecedente de este agente sobre esta especie forestal y también en el Hemisferio Sur.

A fines del año 2008 fue detectada por primera vez en Chile la presencia de Neonectria fuckeliana asociado a cancros y torceduras de tronco en árboles de $P$. radiata de 7 y 15 años de edad (Morales 2009) e inmediatamente se iniciaron las primeras investigaciones orientadas a resolver la relación huésped-hospedante, mediante la caracterización in vitro del anamorfo tipo Acremonium de este hongo (Molina 2010, Molina et al. 2012). Con posterioridad, durante el año 2010, se detectó en Chile la presencia in situ de esporodoquios en tejidos corticales de troncos de $P$. radiata afectados por cancros que también evidenciaban síntomas y signos de Neonectria fuckeliana. El análisis morfológico de estos cuerpos fructíferos desarrollados in vivo, permitió caracterizar taxonómicamente a este agente como Cylindrocarpon cylindroides var. tenue (Morales et al. 2013) el cual, según Booth 1959 y Castlebury et al. 2006, corresponde al estado anamorfo de Neonectria fuckeliana. Cylindrocarpon cylindroides var. tenue fue también reportado en Nueva Zelanda por Gadgil et al. (2003). Según Dick y Crane (2009) y Crane et al. (2009) es un estado anamorfo raramente encontrado en cancros producidos por Neonectria fuckeliana en troncos de $P$. radiata. Probablemente, debido a la infrecuente presencia de $C$. cylindroides como agente asociado a cancros en especies de coníferas, este anamorfo ha sido también poco investigado.

Mediante la obtención de aislamientos multi y monospóricos de $C$. cylindroides, y atendiendo fundamentalmente a las características macro y micromorfológicas manifestadas in vitro, el presente estudio tuvo como objetivo ratificar la relación de este agente como ananamorfo de Neonectria fuckeliana. Para ello, también se realizaron análisis comparativos con cultivos in vitro obtenidos a partir de peritecios de Neonectria fuckeliana, además de análisis moleculares específicos.

\section{MATERIALES Y MÉTODOS}

Obtención de muestras. Las muestras de corteza que contenían peritecios de Neonectria fuckeliana y esporodoquios de $C$. cylindroides fueron colectadas en un rodal de $P$. radiata de 8 años, localizado en la Comuna de Paillaco, Región de los Ríos (Coordenadas UTM: 674164E y 555199S. Elevación aproximada: 200 m s.n.m.). En laboratorio, mediante análisis microscópico se verificó la presencia y estado de conservación de las fructificaciones teleomórficas y anamórficas colectadas, específicamente el estado de madurez de éstas, como una forma de ponderar la fertilidad aparente del material fungoso a utilizar. En el caso específico de los esporodoquios de $C$. cylindroides, se verificó la presencia y estado de conservación de los micro y macroconidios, fundamentalmente de estos últimos, característicos de este estado anamorfo (Figura $1 \mathrm{E}$ ). En general, las muestras colectadas fueron inmediatamente utilizadas 0 en su defecto mantenidas en refrigerador a $5^{\circ} \mathrm{C}$ por hasta cuatro semanas.

\section{Aislamientos de Neonectria fuckeliana a partir de} peritecios. Como material base, se acondicionaron pequeños trozos de corteza de una superficie aproximada de $6 \times 6 \mathrm{~mm}$ y $5 \mathrm{~mm}$ de grosor que contenían peritecios estromáticos de Neonectria fuckeliana. El proceso de desinfección de las muestras ya acondicionadas y luego los aislamientos respectivos, se hicieron en una cámara de flujo laminar a la que se le incorporó una lupa estereoscópica. Los trozos fueron colocados durante 1 minuto en un vaso 
Relación in vitro entre Cylindrocarpon cylindroides y Neonectria fuckeliana - M.Osorio et al.

de precipitado de $100 \mathrm{~mL}$ que contenía Alcohol al $70 \%$, y agitados en forma continua mediante una varilla de vidrio previamente esterilizada. Seguidamente, se realizaron dos lavados en agua destilada estéril, durante 2 minutos cada lavado. Luego de este proceso los trozos de corteza fueron depositados en una placa de vidrio que contenía papel filtro previamente esterilizado en autoclave, y expuestos por algunos minutos a la corriente de aire estéril de la cámara de flujo laminar para permitir el secado superficial de ellos. Con la ayuda de la lupa se individualizaron los peritecios que serían utilizados como inóculo, los cuales mediante una aguja previamente esterilizada, fueron transferidos individualmente a placas que contenían Agar Malta al 2\%. Se realizaron cuatro aislamientos por placa. Las placas conteniendo estos aislamientos fueron puestas en cámara de incubación a $23{ }^{\circ} \mathrm{C}$, sin luz. Este método para la obtención de aislamientos de Neonectria fuckeliana a partir de peritecios, con algunas variantes, entre otras en el proceso de esterilización del material base, emula en parte al utilizado por Molina (2010) y Molina et al. (2012).

Aislamientos multiespóricos de $\boldsymbol{C}$. cylindroides. Debido a la inestabilidad que presentaban los macroconidios de $C$. cylindroides, los que se desprendían fácilmente de las células conidiógenas contenidas en los esporodoquios al ser expuestos a corrientes de agua, se optó por descartar cualquier método de desinfección superficial que contemplara la utilización de productos desinfectantes en estado líquido. Se trató de evitar también el posible efecto letal que sobre los tejidos fungosos a utilizar como inóculo pudiese tener cualquier producto desinfectante. En consecuencia, en cámara de flujo laminar y con la ayuda de una lupa estereoscópica instalada en su interior, mediante una aguja previamente esterilizada, se extrajeron directamente desde los esporodoquios fracciones de tejido fértil de un volumen inferior a $1 \mathrm{~mm}^{3}$, las que fueron transferidas a placas Petri que contenían Agar Malta al $2 \%$. Se realizaron cuatro aislamientos por placa, los que posteriormente fueron puestos en cámara de incubación a $23^{\circ} \mathrm{C}$, sin luz. Las placas fueron observadas periódicamente, para constatar la formación de colonias libres de agentes contaminantes. Las colonias emergidas, fueron posteriormente transferidas en forma individual al centro de placas Petri con Agar
Malta al 2\%, tanto para el estudio de sus características macro y micromorfológicas, como para las posteriores pruebas moleculares específicas.

Aislamientos monospóricos de $C$. cylindroides. Al igual que para los aislamientos multiespóricos, en cámara de flujo laminar y auxiliado de una lupa estereoscópica, mediante una aguja previamente esterilizada se extrajo directamente desde un esporodoquio de $C$. cylindroides no desinfectado externamente, por las razones ya señaladas, una porción de tejido fértil de un volumen no superior a 1 $\mathrm{mm}^{3}$ la que fue transferida a un tubo de ensayo que contenía $10 \mathrm{~mL}$ de agua destilada estéril. La porción de tejido fúngico allí depositado fue macerada, utilizando para ello una varilla de vidrio previamente esterilizada en autoclave. Luego de esto, y aprovechando la facilidad con la que se desprendían los macroconidios al estar expuestos a corrientes de agua, con la misma varilla se revolvió el contenido acuoso presente en el tubo de ensayo, producto de lo cual al cabo de algunos minutos se obtuvo una suspensión concentrada de esporas. A partir de la suspensión concentrada de esporas se realizaron diluciones al $10 \%, 1 \%, 0,1 \%$, y $0,01 \%$. Mediante una Cámara de Neubauer y utilizando alícuotas de la dilución al 10\%, se contabilizó la cantidad de inóculo allí presente. Esta dilución contenía aproximadamente 58.000 esporas por $\mathrm{mL}$, representadas mayoritariamente por macroconidios.

Para obtener los aislamientos monospóricos a partir de cada una de las suspensiones de esporas, incluida la suspensión concentrada, se utilizaron placas Petri que contenían Agar Agua al 3\%. En cada placa se vertió $0,5 \mathrm{~mL}$ de suspensión de esporas, la que fue expandida en toda la superficie del medio de cultivo mediante un rastrillo de vidrio previamente esterilizado. Las placas así inoculadas fueron puestas en cámara de cultivo, sin luz, a $23^{\circ} \mathrm{C}$ para permitir la germinación de las esporas. Luego de 20 horas de realizado los cultivos, se llevó a efecto el primer control del proceso de germinación. Con posterioridad, este proceso fue controlado periódicamente cada 4 horas para visualizar el inicio de la germinación de los macroconidios (Figura 1 F). La visualización del inicio de la formación de las colonias monospóricas se efectuó mediante una lupa esteresocópica instalada en la cámara de flujo, utilizando de preferencia un aumento de $10 \times 2$, y sólo ocasionalmente de $10 \times 4$. 
Relación in vitro entre Cylindrocarpon cylindroides y Neonectria fuckeliana - M.Osorio et al.

Para la mejor visualización del proceso de germinación de los macroconidios, las placas fueron analizadas en posición invertidas, apoyadas sobre un fondo de color negro, y observadas con luz incidente. El marcaje de las colonias monospóricas se efectuó en la cara externa de la parte posterior de las placas Petri luego de 24 a 72 horas de realizado los cultivos, y una vez que las colonias monospóricas ya eran claramente visibles. Se dio preferencia sólo a aquellas colonias incipientes que se encontraban relativamente distantes unas de otras de forma tal de tener la certeza que ellas eran originadas a partir de un solo macroconidio, y que las hifas germinativas y el posterior micelio generado a partir de ellos, no estuviesen entrecruzados con la de otros macroconidios en germinación que se encontraran en las cercanías (Figura $1 \mathrm{G}, \mathrm{H}$ ). Con posterioridad, las colonias monospóricas así demarcadas fueron transferidas a placas con Agar Malta al 2\%, utilizando para ello una fina aguja previamente esterilizada. En cada placa Petri se efectuó sólo un aislamiento y el inóculo (Figura 1 I) fue puesto en el centro de ella. Los cultivos monospóricos de $C$. cylindroides así obtenidos, fueron puestos en cámara de incubación a $23^{\circ} \mathrm{C}$, sin luz, para su desarrollo y estudios tanto de las características macro y micromorfológicas, como para las posteriores pruebas moleculares específicas.

Análisis molecular. Para comprobar la asociación entre $C$. cylindroides y Neonectria fuckeliana a través de métodos moleculares, se tomaron tres cepas de cultivos monospóricos de C. cylindroides (Cyl. 04, Cyl 11, Cyl. 30) a los cuales una vez completado su desarrollo en placas Petri de $8 \mathrm{~cm}$ de diámetro en medio de cultivo Agar Malta 2\%, se les realizó la extracción de ADN según el método descrito por Arismendi et al. (2010), tomando la totalidad del micelio aéreo por medio del rastrillado de la placa. Las regiones de ADN amplificadas fueron la ITS y parte del gen ribosomal $18 \mathrm{~S}$, los partidores utilizados fueron el ITS5, ITS4, y el NS1, NS2 descritos por White et al. (1990). La reacción PCR se realizó en un volumen de $12,5 \mu \mathrm{L}$ y consistió en: $1,25 \mu \mathrm{L}$ de buffer $10 \mathrm{x} ; 25 \mathrm{mM}$ $\mathrm{MgCl}_{2} ; 2,5 \mathrm{mM}$ dNTP's; $10 \mu \mathrm{M}$ de cada partidor; 0,5 $\mathrm{U}$ Taq ADN Polymerasa, Invitrogen; $9,45 \mu \mathrm{L}$ de $2 \%$ PVP, para 1 i L de ADN. El programa en el termociclador fue el siguiente: $94^{\circ} \mathrm{C}$ por 3 minutos, luego 35 ciclos, donde cada ciclo consistió en 30 segundos a $94^{\circ} \mathrm{C}$, 40 segundos a $57^{\circ} \mathrm{C}$ para los partidores ITS y a $50^{\circ} \mathrm{C}$ para el caso de $18 \mathrm{~S}$, luego 1 minuto a $72{ }^{\circ} \mathrm{C}$, para finalmente 7 minutos a $72^{\circ} \mathrm{C}$, y por último mantener a $4^{\circ} \mathrm{C}$.

La separación de fragmentos amplificados se evaluó en geles de agarosa al $1 \%$ teñidos con bromuro de etidio, visualizados en un transluminador de luz UV. La secuenciación de los fragmentos, se realizó a través del servicio de secuenciación automática de MACROGEN en Corea. Una vez obtenidas las secuencias, se procedió a editarlas con el software Chromas lite, luego se utilizó BLAST para confirmar las especies e identificar si existían secuencias homólogas. Por último, las secuencias se alinearon con el programa Clustal W para identificar si existían diferencias entre sí, además de compararlas con la base de datos de Genbank.

\section{RESULTADOS}

Obtención de muestras. Las muestras colectadas de corteza de árboles de $P$. radiata, afectados por cancros asociados a Neonectria fuckeliana, y que presentaban peritecios de este hongo y/o esporodoquios del estado anamorfo $C$. cylindroides, resultaron estar en condiciones muy adecuadas para satisfacer los objetivos del presente estudio. Específicamente, los esporodoquios de $C$. cylindroides, presentaron un estado de madurez y suculencia óptimos como para proveer el inóculo requerido para esta investigación (Figura $1 \mathrm{~A}, \mathrm{~B}, \mathrm{C}, \mathrm{D}$, E). De los macroconidios utilizados, los de 3 septos tenían un tamaño de 32,0 - 50,1 × 4,0 - 5,3 $\mu \mathrm{m}$, los de 5 septos $46,9 \times-63,3 \times 3,3-4,8 \mu \mathrm{m}$, y los de 7 septos $60,0-76,7 \times 3,9-5,5 \mu \mathrm{m}$.

Aislamientos de Neonectria fuckeliana a partir de peritecios. En Agar Malta al 2\% estos aislamientos dieron origen a colonias de color marrón claro a café anaranjado con una leve decoloración en los bordes y escaso micelio aéreo de color blanquecino, y presentaron un desarrollo diametral de $55 \mathrm{a} 60 \mathrm{~mm}$ medidos a los 12 días. Microscópicamente, el micelio aéreo estaba constituido por células conidiógenas 0 fiálides hialinas, septadas, un tanto rectas y con un diámetro que se agudizaba hacia el extremo apical, se presentaban aisladas o formando verticilos ralos con no más de 2 a 3 fiálides, de 27,3 - 94,5 x 2,1 - 2,7 $\mu \mathrm{m}$. En el extremo apical, las fiálides daban origen a conidios que permanecían agrupados semejando a una pequeña gotita de aspecto mucilaginoso 
Relación in vitro entre Cylindrocarpon cylindroides y Neonectria fuckeliana - M.Osorio et al.

(glioconidios) los que se disgregaban en contacto con el agua. Los conidios eran hialinos, cilíndricos a elipsoides, piriformes en algunos casos, unicelulares, de 4,0 - 10,0 x 2,2 - 3,3 $\mu \mathrm{m}$; excepcionalmente se detectó la presencia de conidios unitabicados. Las características macro y micromorfológicas aquí observadas, corresponden a las de la forma asexual del tipo Acremonium (Figura $1 \mathrm{~J}, \mathrm{~K}$ ). No se observaron macroconidios del tipo Cylindrocarpon.

Aislamientos multiespóricos de $C$. cylindroides. Al igual que en el caso anterior, en Agar Malta al 2\% estos aislamientos dieron origen a colonias de color marrón claro a café anaranjado con una leve decoloración en sus bordes, presentaron escaso micelio aéreo y tuvieron un desarrollo diametral de 42 a $65 \mathrm{~mm}$ medidos a los 12 días. Microscópicamente, el micelio aéreo estaba constituido por fiálides hialinas, septadas, un tanto rectas y su diámetro se agudizaba hacia el extremo apical, se presentaban aisladas 0 formando verticilos de no más de 2 a 3 fiálides, de $26,1-87,5 \times 2,1-2,9 \mu \mathrm{m}$. En el extremo apical, las fiálides daban origen a conidios que se mantenían agrupados, dando la apariencia de una pequeña gotita mucilaginosa (glioconidios) los que se disgregaba en contacto con el agua. Los conidios eran hialinos, cilíndricos a elipsoides, piriformes en algunos casos, unicelulares, de 4,0-10,1 x2,2 -3,3 $\mu \mathrm{m}$; excepcionalmente fue posible detectar la presencia de conidios unitabicados. Las características macro y micromorfológicas aquí observada, corresponden a las de la forma asexual del tipo Acremonium (Figura $1 \mathrm{~L}, \mathrm{M}$ ). No se observaron macroconidios del tipo Cylindrocarpon

Aislamientos monospóricos de C. cylindroides. En Agar Malta al 2\% estos aislamientos dieron origen a colonias de color marrón claro a café anaranjado con una leve decoloración en los bordes, presentaron escaso micelio aéreo y tuvieron un desarrollo diametral de 44 a $61 \mathrm{~mm}$ a los 12 días. Microscópicamente, el micelio aéreo estaba constituido por fiálides hialinas, septadas, un tanto rectas y su diámetro se agudizaba hacia el extremo apical, se presentaban aisladas 0 formando verticilos de no más de 2 a 3 fiálides, de $24,6-88,0 \times 2,1-3,2 \mu \mathrm{m}$. En el extremo apical, las fiálides daban origen a los conidios, los que permanecían agrupados, semejando a una pequeña gotita mucilaginosa (glioconidios) los que se disgregaban en contacto con el agua. Los conidios eran hialinos, cilíndricos a elipsoides, en algunos casos piriformes, unicelulares, de 4,1-10,0 $2,1-3,3 \mu \mathrm{m}$; excepcionalmente también, fue posible detectar la presencia de conidios unitabicados. Las características macro y micromorfológicas aquí observadas, corresponden a la de la forma asexual del tipo Acremonium (Figura $1 \mathrm{~N}, \tilde{N}$ ). No se observaron macroconidios del tipo Cylindrocarpon.

Análisis molecular. La seis secuencias obtenidas en el estudio (Cuadro 1) presentaron un tamaño de aproximadamente $470 \mathrm{pb}$ para ambas regiones del genoma nuclear utilizado (ITS y 18S). El BLAST confirmó que las secuencias obtenidas de cultivos monospóricos de $C$. cylindroides corresponden a Neonectria fuckeliana con un $99 \%$ a $100 \%$ de homología para ambas regiones, sin encontrar otras especies con ese nivel de homología. Al mismo tiempo el alineamiento de las tres secuencias para la región ITS mostró un cambio en la base 321 de la cepa Cyl11. En el caso de la región parcial del gen $18 \mathrm{~S}$ no presentaron diferencias entre las secuencias.

Tabla I.Código de accesión a Genbank por cepa y para cada secuencia.

\begin{tabular}{|llcc|}
\hline Especie & Cepa & ITS & 18S \\
\hline C. cylindroides & Cyl04 & KF998193 & KJ161395 \\
C. cylindroides & Cyl11 & KF998194 & KJ161396 \\
C. cylindroides & Cyl30 & KF998195 & KJ161397 \\
\hline
\end{tabular}

\section{DISCUSIÓN}

La nomenclatura y la taxonomía de Neonectria fuckeliana (Booth) Castlebury \& Rossman, desde su origen han sido muy cambiantes y controvertidas. Ello, derivado en parte a que la base de referencia ha estado mayoritariamente representada por muestras disecadas (exsiccate) de museos y de herbarios, cuya antigüedad en algunos casos es de varias décadas, e incluso de más de un siglo, lo que puede tener efectos en su viabilidad. Diferente es el caso, cuando se realizan comparaciones sistemáticas basadas en material fresco, con fructificaciones fértiles y maduras ya presentes, o factibles de inducir. Más aún si a ello se agrega la posibilidad actual de aplicar nuevas técnicas de apoyo, como por ejemplo, microscopía de alta resolución, 0 análisis moleculares de ADN a los especímenes en cuestión. 
Gadgil et al. (2003) identificaron a Nectria fuckeliana C. Booth asociado a cancros en troncos de $P$. radiata, en Nueva Zelanda, lo que constituyó el primer reporte de este hongo afectando en forma natural a plantaciones de esta especie y también el primer reporte de este agente en el Hemisferio Sur (Crane et al., 2009). En base a las características observadas en cultivos, y utilizando como sustrato Agar Malta al 2\%, Gadgil et al. (2003) señalaron a Cylindrocarpon cylindoides var. tenue Wollenweber como el anamorfo de Nectria fuckeliana, en concordancia con la descripción original hecha por Booth (1959).

No obstante, Brayford et al. (2004) pusieron en duda que el estado anamorfo de Nectria fuckeliana fuese $C$. cylindroides var. tenue dado que los cultivos monospóricos realizados por ellos a partir de ascosporas, sólo dieron origen a abundantes microconidios desde conidióforos del tipo Acremonium o Verticillium, y no produjeron macroconidios. Por lo tanto, la ausencia de estos últimos, en combinación con los resultados logrados con la secuenciación de ADN, les indujo a sugerir que la conexión entre Nectria fuckeliana y Cylindrocarpon no era correcta.

Con posterioridad, Castlebury et al. (2006) al investigar la relación filogenética entre Neonectria y Cylindrocarpon en cancros de corteza de especies de Fagus, incluyeron también entre los aislamientos y especímenes examinados a Nectria fuckeliana y $C$. cylindroides. Como resultado de los análisis de ADN, y contradiciendo a lo postulado por Brayford et al. (2004), concluyen que Cylindrocarpon sí correspondía al estado anamorfo de Nectria. Por lo tanto, propusieron transferir de género a Nectria fuckeliana, quedando como Neonectria fuckeliana (C. Booth) Castlebury \& Rossman comb. nov.

Desde el punto de vista de la micología aplicada, y más específicamente desde el punto de vista de la patología forestal, Ilama la atención que no obstante los numerosos estudios realizados tendientes a resolver la relación huésped-hospedante de la presencia de Neonectria fuckeliana en $P$. radiata, las características tanto macro como micromorfológicas in situ e in vitro de los estados anamorfos Acremonium y C. cylindroides, haya sido escasas a nulamente investigadas.
En Chile, inmediatamente de reportada la presencia de Neonectria fuckeliana asociada a crancos en troncos de $P$. radiata (Morales, 2009), se abordó la caracterización macro y micromorfológica del estado anamorfo Acremonium (Molina, 2010; Molina et al. 2012). Lo mismo ocurrió con C. cylindroides, luego de ser reportado (Morales et al. 2013). Ello, como una forma de dilucidar el rol que tanto el teleomorfo como estos dos anamorfos pueden estar representando en la formación de cancros en troncos de $P$. radiata.

Cabe destacar que in situ los esporodoquios de $C$. cylindroides son muy poco frecuentes y además no son fáciles de visualizar debido a que pueden ser enmascarados por la secreción de resina en la región de la corteza afectada por los cancros (Figura 1 A). También, pueden ser confundidos con fructificaciones de color blanquecino correspondientes a otros hongos emergentes en la misma zona del cancro. Coincidiendo en parte con esto, Dick \& Crane (2009) y Crane et al. (2009) señalan que en Nueva Zelanda la presencia de Cylindrocarpon ha sido rara vez reportada en bosques de $P$ radiata con presencia de cancros asociados a Neonectria fuckeliana. Hopkins et al. (2012) hipotetizan que probablemente Cylindrocarpon se produzca con más frecuencia en forma natural, pero los esporodoquios pueden pasar desapercibidos por ser similares a pequeñas gotas de resina. Todo esto podría explicar en parte el que este estado anamorfo haya sido poco investigado en ese país.

En el presente estudio, tanto los aislamientos de Neonectria fuckeliana obtenidos a partir de peritecios, como los aislamientos multi y monospóricos de $C$. cylindroides cuyo inóculo provino de esporodoquios en buen estado de conservación, dieron origen a colonias, células conidiógenas y conidios, característicos del estado anamorfo tipo Acremonium (Figura $1 \mathrm{~J}, \mathrm{~K}, \mathrm{~L}, \mathrm{M}, \mathrm{N}$, N). Esto es concordante con las características micro y macromorfológicas de los cultivos obtenidos por Molina (2010) y Molina et al. (2012), a partir de peritecios de Neonectria fuckeliana, utilizando un método muy semejante al empleado en el presente estudio.

En general, las características macro y micromorfológicas de los cultivos aquí logrados, y 


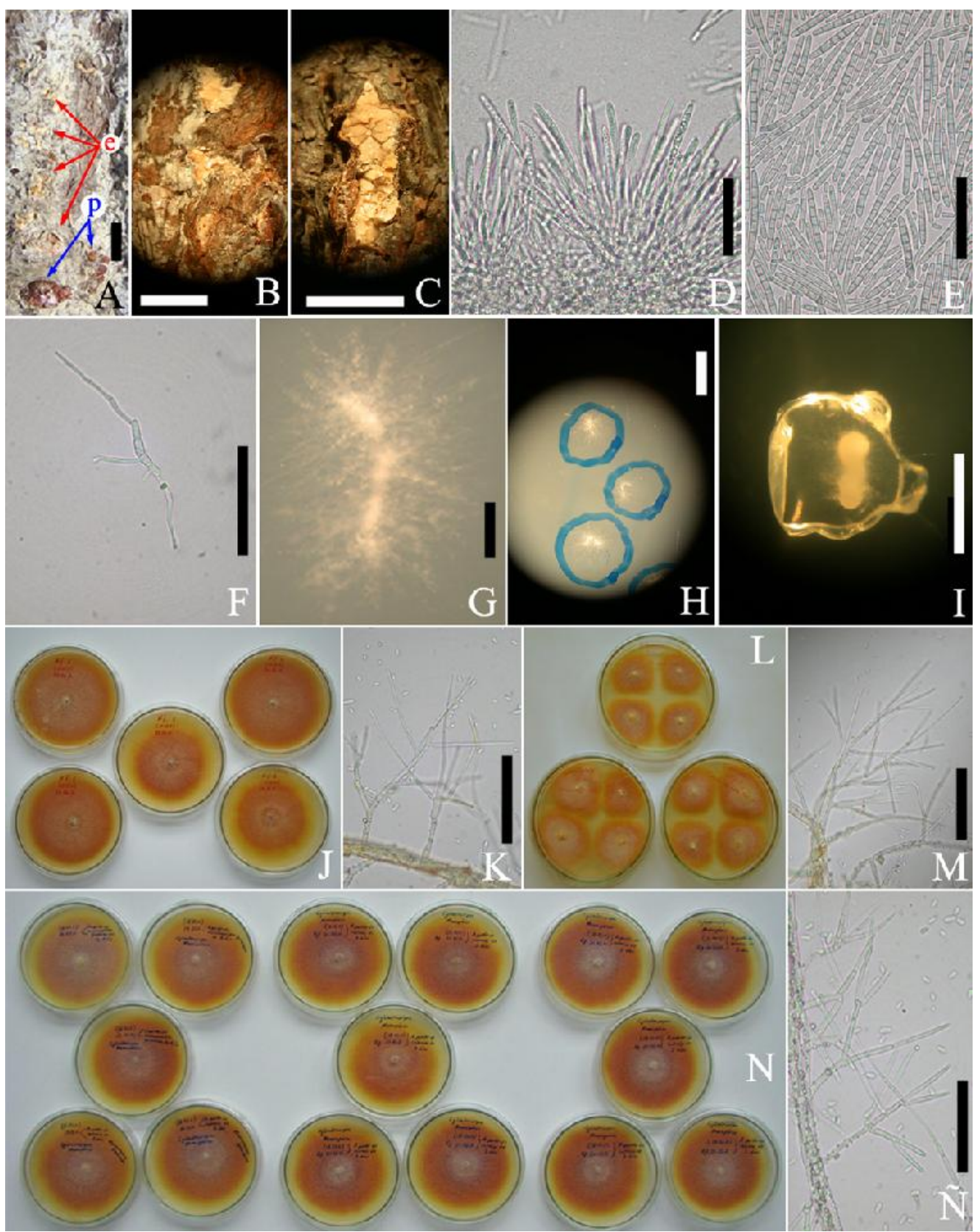

Figura 1. Porción de corteza de $P$. radiata afectada por cancro (A) en la que se observan numerosos esporodoquios de $C$. cylindroides (e) y peritecios estromáticos de Neonectria fuckeliana (p). Esporodoquios erupentes, desgarrando el tejido cortical (B y C). Estrato basal del esporodoquio en el que se observan abundantes células conodiógenas y conidios en formación (D). Micro y macroconidios de $C$. cylindroides (E). Macroconidio de $C$. cylindroides en proceso de germinación in vitro (F). Colonia desarrollada a partir de la germinación de un macroconidio de $C$. cylindroides (G). Conjunto de colonias monospóricas de $C$. cylindroides (H). Trozo de Agar-Agua conteniendo una colonia monospórica de C. cylindroides, utilizada como inóculo (I). Colonias de Neonectria fuckeliana obtenidas a partir de peritecios (J), y fiálides y conidios del tipo Acremonium producidos en ellas (K). Colonias multiespóricas de $\mathbf{C}$. cylindroides (L), y fiálides y conidios del tipo Acremonium producidos en ellas $(\mathbf{M})$. Colonias monospóricas de $C$. cylindroides $(\mathbf{N})$ y detalles de las fiálides y conidios del

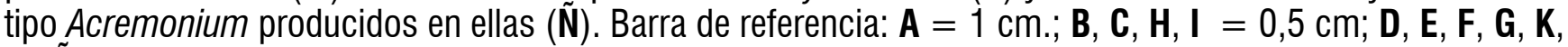
$\mathbf{M}, \tilde{\mathbf{N}}=50$ um. 
Relación in vitro entre Cylindrocarpon cylindroides y Neonectria fuckeliana - M.Osorio et al.

más específicamente aquellas que dicen relación con los microconidios, son también coincidentes con las reportadas por Booth (1979) en la descripción original de Nectria fuckeliana y de su anamorfo $C$. cylindroides var. tenue. Del mismo modo, ellas coinciden con las características macromorfológicas de las colonias y de los microconidios de Nectria fuckeliana obtenidos en cultivos por Gadgil et al. (2003). Cabe destacar que estos últimos autores señalan haber encontrado macroconidios de Cylindrocarpon, pero solamente en cultivos pareados, y particularmente sobre trozos esterilizados de madera de pino.

Las características de los microconidios generados en todos los cultivos obtenidos en el presente estudio, coinciden también con las descritas para los cultivos de Nectria fuckeliana por Brayford et al. (2004), quienes sólo obtuvieron colonias del anamorfo tipo Acremonium, mediante cultivos monospóricos, a partir de ascosporas. Al igual que en el presente estudio, estos autores no lograron encontrar in vitro la presencia de macroconidios. Cabe reiterar que fue esto último, lo que unido a los resultados de la secuencia de ADN, indujo a estos autores a postular que la conexión entre Nectria fuckeliana y Cylindrocarpon, no era correcta.

Los resultados obtenidos en el presente estudio, confirman morfológica y molecularmente la relación de C. cylindroides var. tenue como anamorfo de
Neonectria fuckeliana, lo que está en concordancia con lo señalado por Castelbury et al. (2006) al proponer el cambio de la especie Nectria fuckeliana al actual género Neonectria. Estos resultados son concordantes también con la relación Neonectrial Cylindrocarpon, delimitada en sentido estricto por Chaverri et al. (2011) y reconocida luego por Rossman et al. (2013).

Como conclusión de los resultados obtenidos en el presente trabajo, se confirma que $C$. cylindroides var. tenue, y por ende también el tipo Acremonium aquí analizados, corresponden a estados ananamorfos de Neonectria fuckeliana (syn. Nectria fuckeliana), agente asociado a cancros de tronco en plantaciones de $P$. radiata, en Chile.

Desde el punto de vista patológico forestal, se hace necesario desarrollar estudios in situ tendientes a explicar el rol que le compete a $C$. cylindroides en la relación huésped-hospedante de Neonectria fuckeliana como agente causal de cancros en troncos de $P$. radiata, en Chile.

\section{AGRADECIMIENTOS}

El presente estudio fue desarrollado en el marco del Proyecto Fondo SAG C6-110-NC-13 «Ciclo biológico y aspectos epidemiológicos de Neonectria fuckeliana o Revirado del Pino en plantaciones de Pinus radiata. Estrategias para el control de la enfermedad», cuyo financiamiento se agradece.

\section{REFERENCIAS}

Arismendi N.; Andrade N.; Riegel R.; Carrillo R. (2010). Presence of a phytoplasma associated with witches' broom disease in Ugni molinae turcz. and Gaultheria phillyreifolia (pers.) sleumer determined by DAPI, PCR, and DNA sequencing. Chilean Journal of Agricultural Research 70(1): 26-33.

Booth, C. (1959). Studies of Pyrenomycetes IV. Nectria (part 1). Mycological Papers 73: 56-57. MycoBank, Fungal Databases, Nomenclature and Species Banks, http://www.mycobank.org/Biolomics.aspx? Table $=$ Mycobank\&MycoBankNr_ $=301766$

Brayford, D.; Honda, B. M.; Martini, F. R.; \& Samuels, G. J. (2004). Neonectria and Cylindrocarpon: the Nectria mammoidea group and species lacking microconidia. Mycologia 96 (3):572-597.

Castlebury, L. A.; Rossman, A. Y.; \& Hyten, A. S. (2006). Phylogenetic relationships of Neonectria/ Cylindrocarpon on Fagus in North America. Canadian Journal of Botany 84: 1417-1433.

Chaverri, P.; Salgado, C.; Hirooka, Y.; Rossman, A. Y.; \& Samuels, G. J. (2011). Delimitation of Nectria and Cylindrocarpon (Nectriaceae, Hypocreales, Ascomycota) and related genera with Cylindrocarpon-like anamorphs. Studies in Mycology 68:57-78.

Crane, P. E.; Hopkins, A. J. M.; Dick, M. A.; \& Bulman, L. S. (2009). Behaviour of Neonectria fuckeliana causing a pine canker disease in New Zealand. 
Canadian Journal of Forest Research 39: 2119-2128

Dick, M. A.; Power. M. W. P. \& Carlson, C. A. (2011). Neonectria fuckeliana infection of Pinus radiata nursery stock. New Zealand Plant Protection 64: 183-187.

Dick, M. A. \& Crane, P. E. (2009). Neonectria fuckeliana is pathogenic to Pinus radiata in New Zealand. Australasian Plant Disease Notes 4: 12-14.

Gadgil, P. D.; Dick, M. A.; \& Dobbie K. (2003). Fungi Silvicolae Novazelandiae: 4. New Zealand Journal of Forestry Science 33: 265-272.

Hopkins A. J. M.; Dick M. A.; Carlson C. A.; \& Crane P. E. (2012) Early Investigations into the infection courts used by Neonectria fuckeliana to enter Pinus radiata stems. European Journal of Plant Pathology 132: 537-548.

Molina, E. J. (2010). Caracterización de los estados anamorfos de Neonectria fuckeliana asociados a malformaciones en plantaciones de Pinus radiata D. Don. Trabajo de Titulación, Ingeniero Forestal, Facultad de Ciencias Forestales y Recursos Naturales, Universidad Austral de Chile. 14 p.

Molina, E.; Morales, R.; Valenzuela, E.; \& Vives, I. (2012). Caracterización morfológica de Acremonium sp. asociado a Neonectria fuckeliana en Pinus radiata en Chile. Bol. Micol. 27(2):32-38.

Morales, R. (2009). Detección de Neonectria fuckeliana en Chile, asociado a cancros y malformaciones fustales en plantaciones de Pinus radiata. Bosque 30(2): 106-110.

Morales, R.; Molina, E.; Osorio, M.; Vives, I.; González, C.; \& Carmona, J.C. (2013). Detección del sinanamorfo Cylindrocarpon cylindroides var. tenue sobre cancros causados por Neonectria fuckeliana en Pinus radiata. Bol. Micol. 28(2): 53-57.

Rossman, A. Y.; Seifert, K. A.; Samuels, G. J.; Minnis, A. M.; Schroers, H-J.; Lombard, L.; Crous, P. W.; Pöldmaa, K.; Cannon, P. F.; Summerbell, R. C.; Geiser, D. M.; Zhuang, W-y.; Hirooka, Y.; Herrera, C.; Salgado-Salazar, C.; \& Chaverri, P. (2013). Genera in Bionectraceae, Hypocreaceae, and Nectriaceae (Hypocreales) proposed for acceptance or rejection. IMA Fungus 4(1):41-51.

White T.J.; Bruns S.; Lee S.; \& Taylor J. (1990). Amplification and direct sequencing of fungal ribosomal RNA genes for phylogenetics. In: Innis M.A., Gelfand D.H., Sninsky J.J., \& White T.J. (Eds). PCR Protocols: a guide to methods and applications. Academic Press, New York. pp.315-322. 